\section{Gategory}

Polymer-Supported Synthesis

\section{Key words}

gold nanoparticles

UlImann homocoupling

aryl iodides

$\beta$-bromostyrene

A. MONOPOli,* P. COTUGNo, G. PALAZZO, N. DitARANTO, B. MARIANO, N. CiOfFi, F. CIMINALE, A. NACCI* (UNIVERSITÀ DEGLI STUDI DI BARI 'ALDO MORO', ITALY) Ullmann Homocoupling Catalysed by Gold Nanoparticles in Water and Ionic Liquid Adv. Synth. Catal. 2012, 354, 2777-2788.

\title{
Ullmann Homocoupling in Water or Molten TBAOAc with Gold Nanoparticles
}

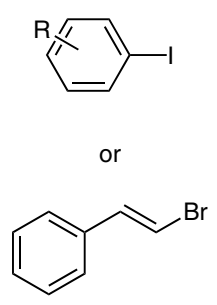

$(0.5 \mathrm{mmol})$

Selected examples:

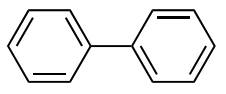

$7 \mathrm{~h}$

$98 \%$ yield (in aq TBAOH) $92 \%$ yield (in TBAOAc)

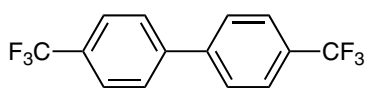

$15 \mathrm{~h}$

$70 \%$ yield (in aq TBAOH) $42 \%$ yield (in TBAOAc)
$\mathrm{Au}(\mathrm{OAc})_{3}(2 \mathrm{~mol} \%)$ glucose $(0.5 \mathrm{mmol})$

$\mathrm{H}_{2} \mathrm{O}(1 \mathrm{~mL})$, TBAOH (1.5 mmol) or TBAOAC $(0.5 \mathrm{~g})$ $90^{\circ} \mathrm{C}$

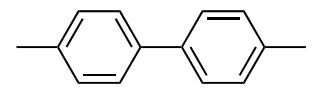

$7 \mathrm{~h}$ $97 \%$ yield (in aq TBAOH) $86 \%$ yield (in TBAOAc)

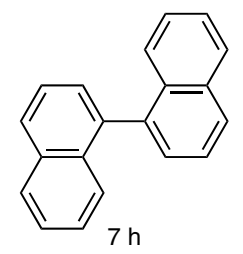

$97 \%$ yield (in aq TBAOH) $63 \%$ yield (in TBAOAc) up to $96 \%$ yield (10 examples)

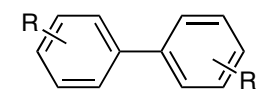

or
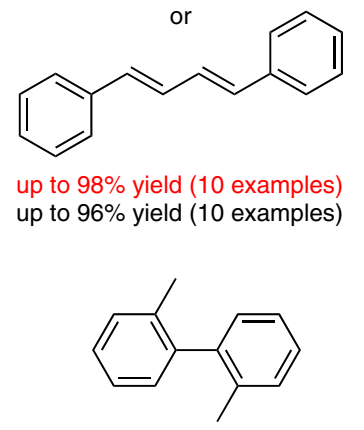

$15 \mathrm{~h}$

$85 \%$ yield (in aq TBAOH) $81 \%$ yield (in TBAOAc)

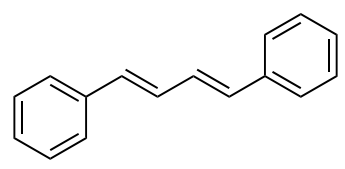

$15 \mathrm{~h}$

$91 \%$ yield (in aq TBAOH) $52 \%$ yield (in TBAOAc)
Significance: Gold nanoparticles, generated in situ from $\mathrm{Au}(\mathrm{OAc})_{3}$ and glucose, catalyzed the Ullmann homocoupling of aryl iodides or $\beta$-bromostyrene in aqueous tetrabutylammonium hydroxide (TBAOH) or in molten tetrabutylammonium acetate (TBAOAC) at $90{ }^{\circ} \mathrm{C}$ to afford the corresponding coupling products in up to $98 \%$ yield (10 examples) or in up to $96 \%$ yield (10 examples), respectively.
Comment: The gold nanoparticles were characterized with TEM, UVNis, DLS, and XPS. The particle size of the nanoparticles was about $1 \mathrm{~nm}$ in aqueous TBAOH and $20 \mathrm{~nm}$ in TBAOAc, respectively. The smaller nanoparticles showed higher catalytic activity because of their lager surfaces. 